\title{
Role of the Autonomic Nervous System in Atrial Fibrillation
}

\author{
Enrique Indalécio Pachón Mateo ${ }^{1}$ (10 \\ Hospital do Coração, ${ }^{1}$ São Paulo, SP - Brazil \\ Short Editorial related to the article: Cardiac Autonomic Nervous System Remodeling May Play a Role in Atrial Fibrillation: A Study of the \\ Autonomic Nervous System and Myocardial Receptors
}

Since the late 1990s, we have been intensely studying the role of the autonomic nervous system in the genesis and maintenance of atrial fibrillation (AF) and neurocardiogenic syncope. ${ }^{1}$

AF can occur both in normal hearts and in those with significant structural changes. ${ }^{2}$ Episodes of AF in young individuals with apparently normal heart have always caught our attention. The fact that these patients often have dysautonomic-like manifestations led us to think that purposeful denervation could be a way to treat these cases, and this technique was pioneered in $2004 .^{3}$ The effect of innervation seems to be not only due to neural stimulation but also by promoting disarray in the atrial syncytial architecture, in the sites of penetration of neurons, which detach the myocardial cells, disconnecting them. This disarrangement also promotes changes that can be detected in the endocardium by the local electrical signal, which we call AF Nests (AFN), and in the case of innervation, we call AFN type I.

The AFN are part of the AF substrate but to be sustained, it is necessary to have a maintainer that we call background tachycardia (BKT). ${ }^{4}$ The AF elimination seems to depend on the elimination of substrate and sustaining factor, according to our observations and the findings of several more recent authors. ${ }^{5}$ The vagal stimulation significantly reduces the refractory period of cardiac cells, facilitating the induction of $\mathrm{AF}^{6}{ }^{6}$ The most interesting is that this alteration in the refractory period is not homogeneous, favoring arrhythmia.

\section{Keywords}

Autonomic Nervous System; Atrial Fibrillation; Cardioneuroablation; Cardiac Nervous System.

\section{Mailing Address: Enrique Indalécio Pachón Mateo •}

Hospital do Coração - Rua Cubatão, 86 Sala 508. Zip Code 04004-030,

São Paulo, SP - Brazil

E-mail: epachon@gmail.com

DOI: https://doi.org/10.36660/abc.20210771
Another important fact is that the regions innervated by the right and left vagus, although partially overlapping, are not precisely the same. ${ }^{7}$ Furthermore, the stimulation of the stellate ganglia or the infusion of sympathomimetics associated with vagal stimulation significantly reduces the AF threshold of the evaluated patients, showing that the balance between the sympathetic and parasympathetic system is primordial for the maintenance of regular cardiac rhythm. The authors of this study also found similar data when studying both the intrinsic cardiac innervation and its receptors. ${ }^{8}$ The work is very well conducted, selecting two very similar groups with the same pathologies, in which the difference is that only one group had AF. The authors were careful to adjust the variables with statistical tools, the size of the left atrium, and the minimum diagnostic time to avoid interference in the results. The samples were also collected in regions close to the main paracardiac ganglia, and therefore sites more densely innervated and previously related to $\mathrm{AF}^{9}{ }^{9}$ In addition, not only nerves but also the various receptors were evaluated. The increased sympathetic innervation in these regions in AF patients corroborates data from the literature, but there is still no adequate explanation to justify it. The unbalance of sympathetic/parasympathetic innervation is certainly arrhythmogenic, as already extensively described..$^{10}$ It is possible that this proves the efficiency of the use of beta-blockers in the treatment of many cases of $\mathrm{AF}$, restoring the balance between the two systems, although the number of receptors was not modified by the use of this medication as observed in this paper.

It was clear from the data obtained in this article that intrinsic cardiac innervation plays a crucial role in maintaining $\mathrm{AF}$, regardless of structural heart disease. The treatment of this arrhythmia should include the approach of the autonomic nervous system, whether through the use of drugs or even through the ablation of these more densely innervated regions so that we can have more robust and lasting results. In this way, we consider it fundamental to insist deeply in the research of the autonomic nervous system of the heart as described in this article, for understanding the genesis of the diverse types of $\mathrm{AF}$, as well as to identify different forms of treatment of this arrhythmia that is so prevalent today in the general population. 


\section{References}

1 Pachon MJC, Pachon MEI, Pachon MJC, Lobo TJ, Pachon MZ, Vargas RN, et al. A New Treatment for Atrial Fibrillation Based on Spectral Analysis to Guide the Catheter RF-Ablation. Europace. 2004;6(6):590-601. doi: 10.1016/j. eupc.2004.08.005.

2 Cintra FD, Figueiredo MJO. Atrial Fibrillation (Part 1): Pathophysiology, Risk Factors, and Therapeutic Basis. Arq Bras Cardiol. 2021;116(1):129-39. doi: 10.36660/abc.20200485.

3 Pachon JC, Pachon El, Pachon JC, Lobo TJ, Pachon MZ, Vargas RN, et al. "Cardioneuroablation"--New Treatment for Neurocardiogenic Syncope, Functional AV Block and Sinus Dysfunction Using Catheter RF-Ablation. Europace. 2005;7(1):1-13. doi: 10.1016/j.eupc.2004.10.003.

4 Pachón-M JC, Pachón-M EI, Santillana P TG, Lobo TJ, Pachón CTC Pachón-M JC, et al. Ablation of "Background Tachycardia" in Long Standing Atrial Fibrillation: Improving the Outcomes by Unmasking a Residual Atrial Fibrillation Perpetuator. J Atr Fibrillation. 2017;10(2):1583. doi: 10.4022/ jafib.1583.

5 Oketani N, Lockwood E, Nademanee K. Incidence and Mode of AF Termination During Substrate Ablation of AF Guided Solely by Complex Fractionated Atrial Electrogram Mapping. Circulation 2008;118(Suppl 18):925. doi: 10.1161/circ.118.suppl_18.S_925-a.
6 Pachon M JC, Pachon M El, Santillana P TG, Lobo TJ, Pachon CTC, Pachon M JC, et al. Simplified Method for Vagal Effect Evaluation in Cardiac Ablation and Electrophysiological Procedures. JACC Clin Electrophysiol. 2015;1(5):451-60. doi: 10.1016/j.jacep.2015.06.008.

7 Pachon-M El, Pachon-Mateos JC, Higuti C, Santillana-P TG, Lobo T, Pachon $\mathrm{C}$, et al. Relation of Fractionated Atrial Potentials with the Vagal Innervation Evaluated by Extracardiac Vagal Stimulation During Cardioneuroablation. Circ Arrhythm Electrophysiol. 2020;13(4):e007900. doi: 10.1161 CIRCEP.119.007900.

8 Oliveira IM, Silva EL Jr, Martins YO, Rocha HAL, Scanavacca MI, Gutierrez PS A Remodelação do Sistema Nervoso Autônomo Cardíaco pode Desempenhar um Papel na Fibrilação Atrial: Um Estudo do Sistema Nervoso Autônomo e Receptores Miocárdicos. Arq Bras Cardiol. 2021; 117(5):999-1007.

9 Driessen AHG, Berger WR, Krul SPJ, van den Berg NWE, Neefs J, Piersma FR, et al. Ganglion Plexus Ablation in Advanced Atrial Fibrillation: The AFACT Study. J Am Coll Cardiol. 2016;68(11):1155-65. doi: 10.1016/j. jacc.2016.06.036

10 Xi Y, Cheng J. Dysfunction of the Autonomic Nervous System in Atria Fibrillation. J Thorac Dis. 2015;7(2):193-8. doi: 10.3978/j.issn.20721439.2015.01.12. 